\title{
Strata control monitoring in a contiguous seam depillaring working
}

\author{
Sandeep K Sahoo, A Galav, B Behera, Sanjay K Sharma and GSP Singh \\ Department of Mining Engineering, \\ Indian Insitute of Technology (BHU) \\ Varanasi, India \\ sandeep.sahoo87@gmail.com
}

\begin{abstract}
Most of the underground coal mines in the Indian Geo-mining conditions are developed and depillared by Bord and Pillar method. Caving behaviour and strata control are the major concerns to be considered while extraction of coal seams in such workings. This paper describes the results of a scientific strata control monitoring study during depillaring in a contiguous seam working. It includes instrumentation for determining the induced stresses in the pillars and roof-floor convergence in the galleries and junctions with distance from the goaf edges in the working. The mining induced stresses on the pillars were observed to be more in the top seam than that in the bottom seam working. Convergence monitoring was done with Telescopic Convergence Indicators (TCI) and Remote convergence recorders. In general, higher convergence was observed in the junctions as compared to the galleries. The junctions located at distant location suffered more convergence than the galleries is nearer to the goaf edge. Based on the field observation, convergence classification has also been done in terms of average distance of the goaf edge from the point of observation to assess the state of 'No-convergence', 'Initial convergence' and 'Maximum convergence'. The convergence observed in the bottom seam is more than that of the top seam.
\end{abstract}

Keywords-caving behaviour; strata control; contiguous workings; convergence; depillaring; mining induced stress; stress meters

\section{INTRODUCTION}

Bord and pillar is the most commonly used underground coal mining method in India. According to the Coal Mines Regulations 1957, contiguous seams have parting thickness less than $9.0 \mathrm{~m}$ [1] but not less than $3 \mathrm{~m}$ [2]. The factors affecting the parting stability in such workings are thickness of parting, depth of cover, lateral eccentricity between the lower and upper seams, horizontal in-situ stress, RMR and extraction ratio [3]. Underground mines are overcoming challenges to extract the coal pillars with safety where coal seams are contiguous because of which the issues of strata control and parting stability in the contiguous seams are more pronounced while depillaring. The coal is locked-up in the form of developed pillars is very difficult to extract in adverse geo-mining conditions [4]. This causes sudden caving of the goaf which endangers the depillaring working of the contiguous sections which affects the pillar stability.

Pillar stability depends on two types of Stresses-Mining Induced Stresses and In-situ Stresses. Mining Induced stresses are dynamic and influenced by the different stages of underground coal mining activity whereas; in-situ stresses are static in nature [5-7]. Stability and caving behaviour of strata at the time of depillaring is controlled by mining induced stresses. These induced stresses are influenced by distribution and re-distribution in the immediate roof over the galleries, junctions and the edges and corners of pillars. Rock instrumentation is done in the mine working for measuring induced stresses and associated displacement in strata. Caving occurs when the vertical gravity force exceeds the shear resistance force in between the two beds [8].

Convergence is the movement of roof and floor in a vertical plane. It indicates the elasto-plastic response in rocks with simultaneous advancement of goaf-edge supports, thereby shifting the line of pillar extraction. It is caused due to redistribution of induced vertical and horizontal stresses in the aforementioned mine workings. A large area of roof in the form of overhang in the goaf affects convergence which is not followed by regular caving. Convergence is also considered as a vital monitoring parameter to ensure parting stability, movement of the strata while recovering coal with safety at the time of depillaring particularly, at the time of splitting, slicing and formation of ribs.

The rock instrumentation plays a major role in the investigative study of the strata movement in the contiguous seams where the parting stability problem between the top and bottom seams exists. Convergence monitoring and Stress measurement are important parametrical approaches for assessing safety at the time of depillaring in the contiguous workings. Strata monitoring study conducted by (Singh et al., 9) at a depth of $75-80 \mathrm{~m}$, involved instrumentation to investigate the interaction of the top seam and standing pillars in the bottom seam. RCI recorded $7 \mathrm{~mm}$ of average convergence in top seam and $1 \mathrm{~mm}$ in bottom seam. Stress meter recorded a value of $0.23 \mathrm{MPa}$ when it was $12 \mathrm{~m}$ away from the goaf edge, and $0.84 \mathrm{MPa}$ at $5 \mathrm{~m}$ inside the goaf edge. [9]. Mandal et al.(2008) conducted instrumentation study in the contiguous seams, where weak and laminated roof parting existed in the coal seam, at a depth of cover varying from 25 to $170 \mathrm{~m}$. Convergence was detected in the stations from the goaf edge at a distance of $120 \mathrm{~m}$ in top section as compared to $135 \mathrm{~m}$ in bottom section and the stress measured to $1.8 \mathrm{MPa}$ in top seam and 0.35 MPa in the bottom seam was observed [10]. In 
one of the strata instrumentation study (Singh et al, 3) for evaluation of parting stability and caving behaviour, cumulative convergence at the face was observed to be $3 \mathrm{~mm}$ per day, where full parting caved down completely at a cover depth of about $80 \mathrm{~m}$ with a parting thickness of $2-3 \mathrm{~m}$. The stress meter observations revealed induced stress of $0.84 \mathrm{MPa}$ at the top section and $0.32 \mathrm{MPa}$ at bottom section, whereas convergence meters showed $5 \mathrm{~mm}$ in Top section and $4 \mathrm{~mm}$ in Bottom section of the working. [3].

This paper presents the findings of a strata behaviour monitoring study to quantify roof-floor convergence in a contiguous seam depillaring working and to determine induced stress on pillars in this process. The results obtained from the implementation of rock instrumentation plan at particular locations in the working so as to monitor the response of the rock structure throughout the life of the panel. The effect of mining induced stress on the pillars was studied with respect to advancement of the goaf edge which indicates the pillar response.

\section{GEO-MINING DeTAILS}

The strata monitoring study was conducted in 24L/19D panel in Bhatgaon colliery SECL which was contiguous in nature. It has two seams LPP (Lower Patpahari Seam) and UPP (Upper Patpahari Seam) which has parting of thickness varying from 3 to $6 \mathrm{~m}$. The average thickness of the seam was $2.4 \mathrm{~m}$. The immediate roof of the UPP seam was formed of the medium grained pebbliferous sandstone.

The underground working in the two seams is developed and depillared by Bord \& Pillar Method of Mining. The depillaring of the pillars is in the form of diagonal line of extraction in the entire panel. The depillaring of pillars was undergone by splitting and slicing methods. The panel is developed into a number of pillars formed by driving galleries in between the adjacent pillars of nearly regular sizes. The two types of galleries crossing each other in the workings are the Level gallery and the Dip-rise gallery. There are five main level galleries from $24 \mathrm{~L}$ to $28 \mathrm{~L}$ and dip galleries enumerated from 19D to 24D.The dip is the direction from $24 \mathrm{~L}$ to 28L.During depillaring of pillar, a split gallery was driven parallel to the main level gallery which subdivides the pillar into two stooks. Further, the slices are driven parallel to the dip-rise gallery dividing each pillar into four stooks but leaving the last slice of $3 \mathrm{~m}$ width called as rib pillar, which acts as temporary support pillar nearer to goaf.

Depillaring of pillars commences from the dip to rise side following diagonal line of extraction. In addition to that, Splitting of the pillars was done upto one pillar ahead of the pillar under extraction. Splitting and Slicing of pillars affects the strata stability of overlying seam. To maintain the strata stability, there should be simultaneous extraction in both the seams separated by parting of $3 \mathrm{~m}$ and the pillars of the seam are superimposed with respect to other. According to CMR 1957, splitting of the pillars should not effect to a distance greater than the length of two pillars during extraction of pillars. In addition to that,

Splitting of pillars is restricted to maximum of four pillars where pillar extraction is about to begin in a district [11]. As the depillaring proceeds, a large area of the exposed roof is formed in the goaf in the form of overhang. The cantilevering effect of these overhangs induces the vertical stress on the adjoining pillars nearer to the line of extraction. In accordance with the proposed working, strata control instrumentation plan was implemented with the extraction of the pillars so as to ensure safer depillaring in the contiguous workings. This ultimately approaches the objective of the convergence monitoring and vertical stress due to overlying strata affecting the pillars, which will help in the prediction of roof fall with the help of instrumentation. The salient geo-mining parameters of the workings are summarized in Table I.

The roof properties of the seam (Table II) are assessed from the bore-hole data. It shows that although the content of sandstone in the overlying roof strata was quite high, the overall RQD of the formation was upto $49 \%$. The roof is not hard and massive so it does not seems too difficult to cave. If the parting thickness were $3-6 \mathrm{~m}$, then the extraction by superimposed pattern takes. But if the parting is $6 \mathrm{~m}$, then UPP is advanced to a distance of one pillar.

\section{STRATA CONTROL INSTRUMENTATION}

The effect of the approach of the goaf line on the convergence of the roof and the induced stress on pillars is studied with the help of the rock instrumentation. A UID (Unique Identification Numbering) system was adopted for all the instruments. It comprised the location of a particular monitoring point, the seam where it are located with the serial number assigned, level and dip of the location.

The instrumentation study was conducted with the help of different instruments including Telescopic Convergence meter, Dual-Height Tell-Tale, Auto-Warning Tell-tale, Stress meters

TABLE I. GEO-MINING PARAMETERS OF THE EXPERIMENTAL PANEL

\begin{tabular}{|l|l|l|}
\hline $\begin{array}{l}\text { Sl. } \\
\text { No. }\end{array}$ & Parameter & Value/Magnitude \\
\hline 1 & Depth of Cover, $\mathrm{m}$ & 42 \\
\hline 2 & Thickness of the UPP (Upper Seam), $\mathrm{m}$ & $2.2-2.9 \mathrm{~m}$ \\
\hline 3 & Thickness of the LPP (Lower Seam), $\mathrm{m}$ & 1.7 to 2.5 \\
\hline 4 & Parting thickness, $\mathrm{m}$ & 3 to 6 \\
\hline 5 & Gassiness & Degree I \\
\hline 6 & Incubation period, months & 12 \\
\hline 7 & Pillar Size (centre to centre) & $24 \mathrm{~m} \times 24 \mathrm{~m}$ \\
\hline 8 & Gallery Size & $4.5 \mathrm{~m} \times 2 \mathrm{~m}$ \\
\hline 9 & RMR & $50-69$ \\
\hline
\end{tabular}

TABLE II. DETAILS OF THE BOREHOLE SEAMS

\begin{tabular}{|l|c|c|c|c|}
\hline Parameter & \multicolumn{4}{|c|}{ Borehole and location } \\
\hline & $\begin{array}{c}\text { CBBB-19 } \\
\text { (55D/23L) }\end{array}$ & $\begin{array}{c}\text { CBBB-32 } \\
\text { (55D/22L) }\end{array}$ & $\begin{array}{c}\text { CBBB-36 } \\
\text { (43D/35L) }\end{array}$ & $\begin{array}{c}\text { CBBB 40 } \\
\text { (37D/35L) }\end{array}$ \\
\hline $\begin{array}{l}\text { Depth of the } \\
\text { UPP seam }\end{array}$ & 60.4 & 60.1 & 62 & 58.05 \\
\hline $\begin{array}{l}\text { \% of } \\
\text { sandstone }\end{array}$ & 82 & 92 & 83 & 94 \\
\hline
\end{tabular}

conical tip of TCR rod was fixed both at roof top and 
and Convergence Recorders. A detailed instrumentation plan showing the location of the convergence measurement stations, stress meters and Auto-warning tell-tell is given in Fig.1.

floor bottom. The distance between the two reference points of roof and floor was measured by extending the movable upper telescopic rod which has reference scale for taking measurements. Cumulative convergence measurements were taken on a daily basis and it was subtracted with previous readings for evaluating the convergence.

Convergence recorders were installed at the middle of the line of extraction in each of the two seams in panels for determining the goaf edge convergence. Convergence recorders had a drum which rotated for twenty-four hours and gives the observation for each day. Two Convergence recorders, one in each seam were installed.

\section{A. Dual Height Tell Tale}

The dual height tell-tale extensometer has been installed at each and every junction of the top and bottom seams to monitor the roof rock displacement.

\section{B. Auto-Warning Tell-Tale}

A total of four Auto-warning tell-tale has been installed in the two seams with 2 in LPP and 2 in UPP for monitoring the rock displacement at the junctions. It warns by having three coloured markings $0-20 \mathrm{~mm}$ in green, $20-50 \mathrm{~mm}$ in blue and $50-70 \mathrm{~mm}$ in red.

\section{Stress Meters}

The stress meters with its read-out unit are used for measuring the induced vertical stress on the pillars to be studied. A total of six vibrating wire stress meters was installed in three pillars in each seam at exactly same location in both of the seams. They are installed in the pillars (Fig. 1) so as to monitor the vertical stress with the regular advancement of goaf line. It is installed within the hole of $36 \mathrm{~mm}$ diameter and $3 \mathrm{~m}$ length in the demarcated position of the pillar keeping in view that while splitting and slicing of the allocated pillar which should be kept safe. The stress meter transducer with the wedge of dia. $37 \mathrm{~mm}$ was installed so that it fitted well with the transducer in the borehole.

The instrument has a vibrating wire transducer which is clipped with the Read-out unit wires while taking reading for stress measurements.

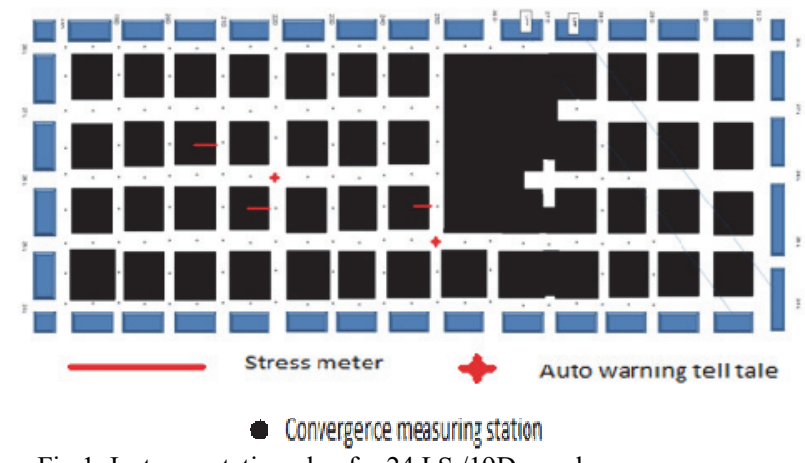

Fig.1. Instrumentation plan for 24 LS /19D panel

\section{OBSERVATIONS}

Strata behaviour observations were made with the help of different instruments set for the purpose for giving condition of the strata while achieving safer extraction. The observations derived from the rock instrumentation helped in continuous surveillance on the caving behaviour of roof, roof stability and vertical stress measurement in contiguous seams having thinner parting. The observations of the stress meter and convergence monitoring were recorded and graphical plots were obtained against the line of goaf advancement.

\section{A. Convergence Monitoring Stations (CMS)}

Convergence Monitoring Stations are installed to study the influence of the goaf edge on the non-elastic convergence of the strata, when it approaches nearer. Convergence monitoring stations were installed at every junction of the level and dip-rise gallery and at a distance half of the width of pillar i.e. in gallery and it should be at the middle of the Gallery cross-section. All the stations were observed in accordance to the state of convergence with respect to the distance from the goaf edge and described as 'No Convergence', 'Initial Convergence' and 'Maximum Convergence'. 'No convergence' state is observed at the point of observation if the goaf edge is too far. 'Initial convergence' is observed when the point of observation comes under the influence of front abutment stress which is distributed within 1.5-2 times the size of the pillar. 'Maximum convergence' state was observed as $8 \mathrm{~mm}$, when the goaf edge was at a distance of $6.5 \mathrm{~m}$ behind the Convergence Measuring Station. Galleries are the locations where the edges of adjacent pillars are on either side whereas Junctions are described as the locations having corners of adjacent pillars where higher stresses are induced.

\section{B. Top Seams 24LS/18D Panel}

Galleries having points of 'No Convergence' state at a limit of 22.57-38.86m, 'Initial Convergence' at $10.58-22.36 \mathrm{~m}$ and 'Maximum Convergence' at 7.75-8.71m. Similarly, Junctions have points of 'No Convergence' state at $24.25-42.53 \mathrm{~m}$, 'Initial Convergence' at 13.43-24.64m and 'Maximum Convergence' at 7.25-11.86 m. Fig. 2 shows convergence plot of Station in UPP at 25L. 'Initial Convergence' is limiting from -1 to $-2 \mathrm{~mm}$ whereas Maximum convergence is limiting from -3 to $-5 \mathrm{~mm}$. The distance limit of convergence in the galleries is less than the junctions. Hence the effect of convergence on junctions is more than that of galleries.

\section{Bottom Seams $24 L S / 18 D$ panels}

Galleries have point of 'No convergence' state at 23.0$57.0 \mathrm{~m}$, 'Initial Convergence' at $14.0-23.0 \mathrm{~m}$ and 'Maximum Convergence' at $8.5-14.0 \mathrm{~m}$. Junctions have point of 'No Convergence' state at $23.0-65.0 \mathrm{~m}$, 'Initial Convergence' at $15.0-23.0 \mathrm{~m}$ and 'Maximum Convergence' at $4.5-15.0 \mathrm{~m}$. The bottom seams have more convergence effect as compared to top seams due to parting and caving of top seam in combination with overburden of shallow depth of $42 \mathrm{~m}$. Initial Convergence was observed from -1 to $-3 \mathrm{~mm}$. 


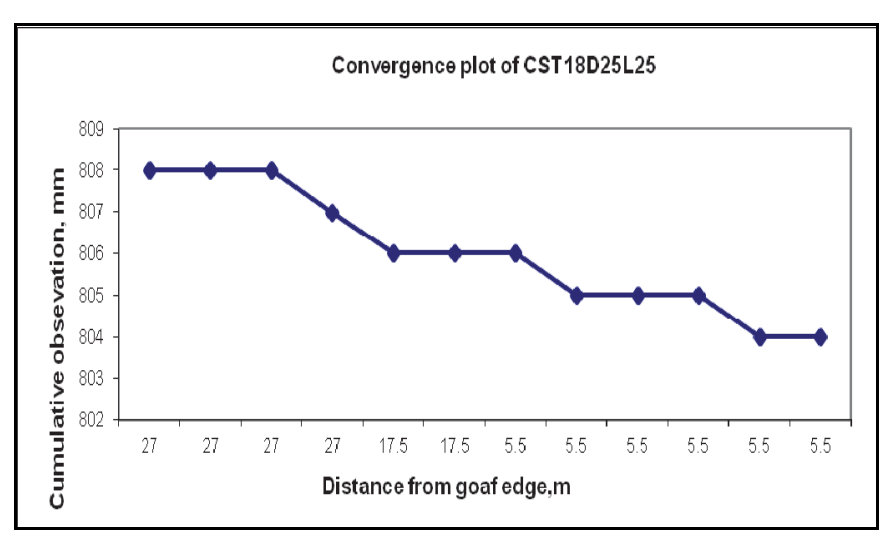

Fig. 2. Convergence plot of 25L in Top Seams

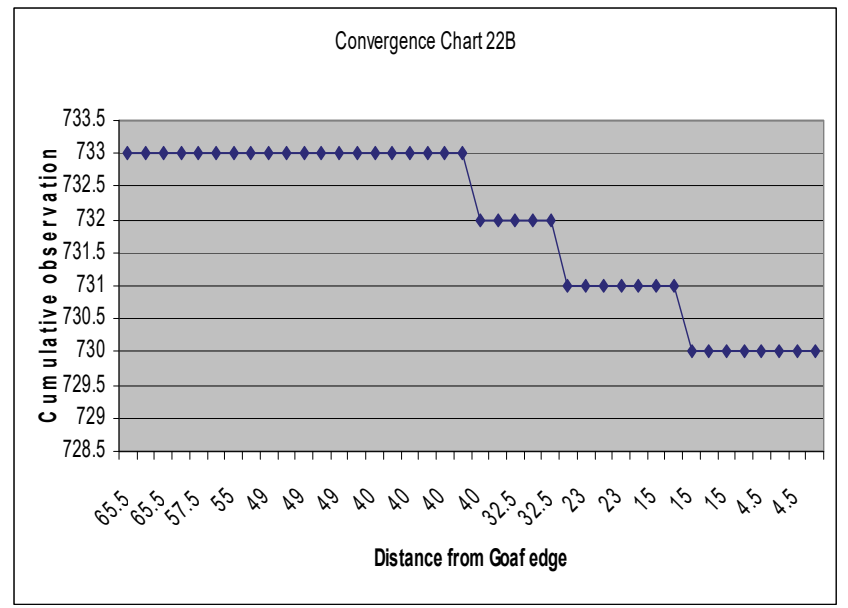

Fig. 3. Convergence plot of $25 \mathrm{~L}$ in Bottom Seams

Whereas Maximum convergence is from -4 to $-6 \mathrm{~mm}$. The following figure in Fig. 3, show convergence in bottom seam at $25 \mathrm{~L}$. The convergence of different station was recorded against the distance of the goaf edge in bottom seam.

\section{Stress meter Observations}

The stress meters were monitored on daily basis to obtain their response for estimating stress induced on the pillars with retreat of diagonal line of extraction. It is observed that up to $40 \mathrm{~m}$ distance from the goaf edge, the abutment stress induced in the pillar is very slow and marginal in nature.

This is confirmed by the convergence study conducted in the distance from the goaf edge, the abutment stress induced in the pillar is very slow and marginal in nature. This is also confirmed by the convergence study conducted in the galleries where initiation of roof-floor convergence was noted as the goaf edge approached within a distance of 1.5 times the pillar width. Length of vibrating wire of the stress metre is inversely proportional to its time period and hence, directly proportional to frequency, which in turn proportional to induced stresses.

\section{E. Top seam 24LS/18D Panel}

In the top seam three stress meters were installed. Each and every stress meters are allocated in the location with the assigned UID which is given in the Fig.4.The Stress meter plan in the figure 4 describes the location and direction of Stress meter installed in the pillar.

The value of induced vertical stress is a function of distance from the goaf edge for the stress meter installation. The location and direction of stress meter is shown in Fig.4. The vertical stresses increase in a gradual and less steep slope which marks that rate of increment of induced vertical stress was less with the advancement of the goaf edge. The relation is plotted for a typical stress meters of UID SM22UPP26L21.5R in the upper seam and is shown in Fig.5.There were no vertical stresses observed from the readings of Stress meter when it is at a distance of $64.5 \mathrm{~m}$ from the goaf edge. Slow and marginal abutment stresses were observed when goaf edge is at a distance $52.5 \mathrm{~m}$. The observations were obtained from the stress meter till the depillaring of the pillar at the commencement of panel.

The maximum stress of $7.2 \mathrm{MPa}$ was observed when goaf was nearer to the pillar containing the stress meter at a distance of $10 \mathrm{~m}$. The abutment stresses in the top seam is maximum than that of the bottom seam.

\section{F. Bottom Seams 24LS/18D Panel -}

Similarly, Stress meters in Bottom seams are also assigned with the UIDs. The locations of three stress meters that was installed within the pillars are shown along with the direction of dip in accordance to the Figure 6 given below.

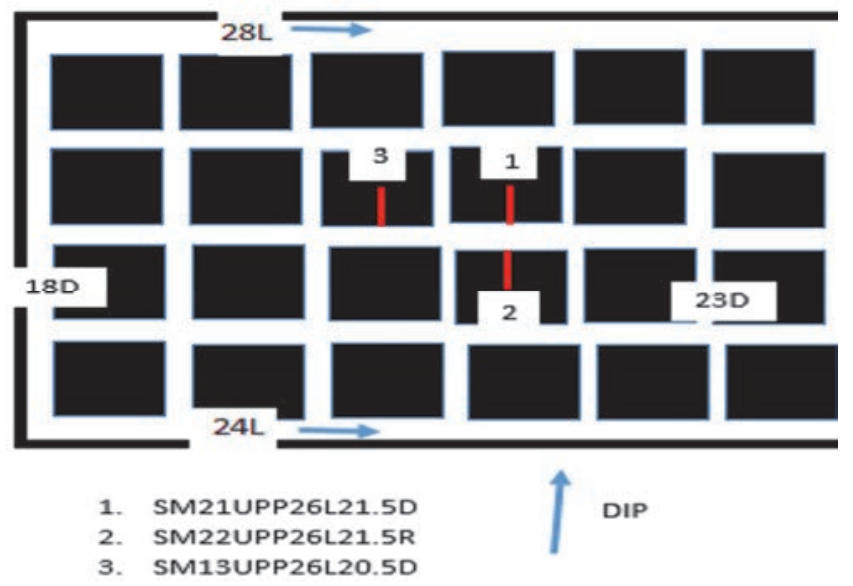

Fig. 4. Stress meter plan of the Top panel

The stress meters were marked as 1', 2' and 3' with their assigned UID's. Figure 7 shows the graphical plot of the stress meter at location 1' having UID assigned SM15LPP26L21.5D. Observations of Stress Meter indicates that abutment stress do not affect pillars when the goaf edge is at $83 \mathrm{~m}$, then it gradually increases slowly when goaf edge is at a distance of $71 \mathrm{~m}$. Then after reaching $40.5 \mathrm{~m}$, the abutment stress at the pillar is $0.96 \mathrm{MPa}$. After this peak, the pillar is destressed to an extent of $0.4 \mathrm{MPa}$ which then increases. This clearly indicates the fall of goaf which destresses the roof and after advancing of line of extraction to some extent, the abutment stresses increases as the roof exposure is larger. The wire is cut as indicated in figure for which further observations were indistinctly fluctuating. 


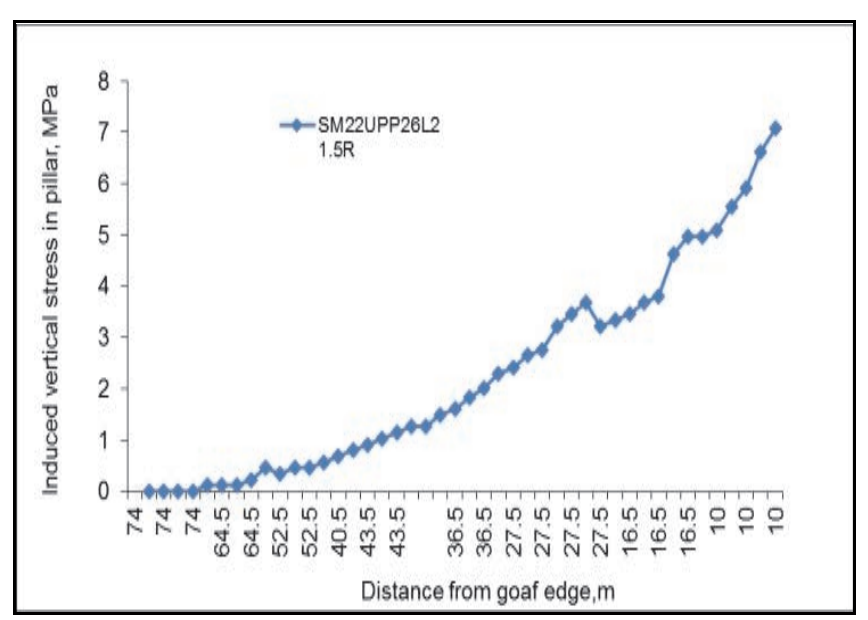

Fig. 5. Stress meter SM22UPP26L20.5D

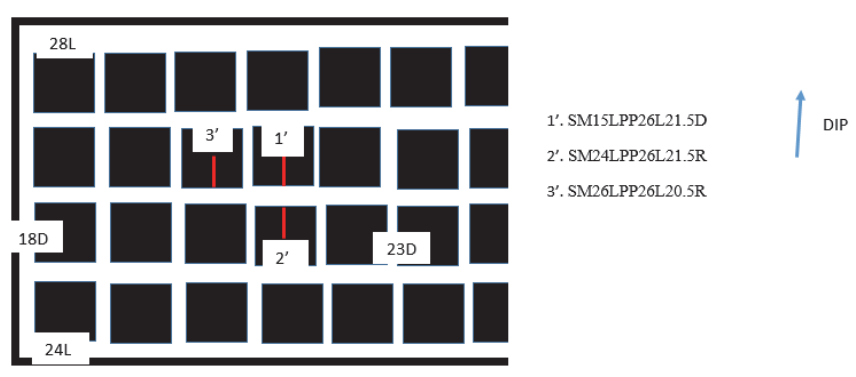

Fig. 6. Instrumentation plan of Stress meters in LPP.

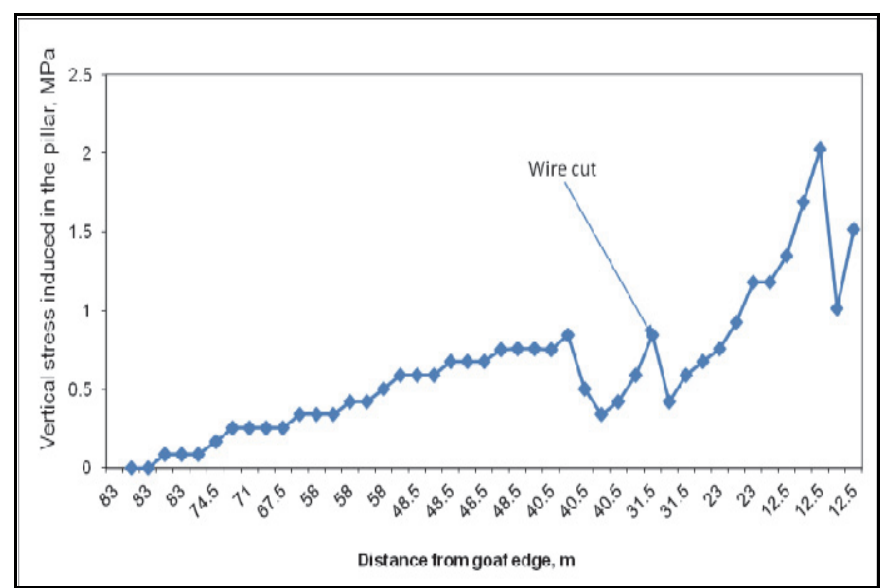

Fig. 7. Induced Stress plot of the SM15LPP26L21.5D

\section{CONCLUSION}

Based on the results of convergence study conducted in Top seam, Initial and Maximum Convergence at junctions at a distance of $13.43-24.64 \mathrm{~m}$ and $7.25-11.86 \mathrm{~m}$ from the goaf edge are larger as compared to galleries at a distance of $10.58-22.36 \mathrm{~m}$ and $7.75-8.71 \mathrm{~m}$ respectively. Similarly in Bottom seam, junctions having initial and the maximum convergence at a distance of $15-23 \mathrm{~m}$ and $4.5-15 \mathrm{~m}$ from the goaf edge are larger as compared to galleries having corresponding values at $14-23 \mathrm{~m}$ and $8.5-14 \mathrm{~m}$ distance from the goaf line. Convergence rate from its initial to maximum value is greater in junctions as compared to that in the galleries. At initial stage, less convergence is induced in Bottom seam than that in the Top seam because of the stress shadowing effect as the former is protected by the standing pillars in the top seam. But, when goaf edge approaches nearer to the monitoring station, maximum convergence in Bottom seam is more than the Top seams because of the collapse of roof of the top seam and the parting. This destresses the top seam and parting instability also increases. The mining induced stress in the Top seams was 7.7 MPa at a distance of $10 \mathrm{~m}$ as compared to $2 \mathrm{MPa}$ in the bottom seams at a distance of $12.5 \mathrm{~m}$, from the goaf edge. The mining induced stresses in the pillars of the Top seam are higher due to load of the overburden and is destressed by caving in the goaf.

\section{ACKNOWLEDGEMENT}

The results of the study presented in this paper forms part of a project sponsored by SECL. The authors are obliged to the mine management for their valuable co-operation during the field observation. The views expressed in this paper are those of the authors and not necessarily of the institute to which they belong.

\section{REFERENCES}

[1] R. Singh, S.K. Singh, A. Kushwaha, A. Sinha, "Stability of the parting between coal pillar workings in level contiguous seams during depillaring,” Int. Jour. Rock Mech Min Sci, vol. 55, pp 1-14, 2012.

[2] R. Singh, "Staggered development of a thick coal seam for full height working in a single lift by the blasting gallery method," Int. Jour. Rock Mech Min Sci, vol. 41, pp 745-759, 2004.

[3] R. Singh, P.R. Sheorey, D.P. Singh, "Stability of the parting between coal pillar workings in level contiguous seams," Int. Jour. Rock Mech Min Sci, vol.39 pp 9-39, 2002.

[4] R.N. Gupta and A.K. Ghose, "Strata support interaction on a powered support longwall face under a massive dolerite sill -a study," In: Proceedings of the 11th international conference on ground control in mining, Wollongong, pp 140-149, 1992.

[5] R. Singh, T.N. Singh, B.B. Dhar, "Coal pillar loading for shallow mining conditions," Int J Rock Mech Min Sci, vol.33, no. 8, pp 757768, 1996.

[6] P.R. Sheorey, "A theory for in situ stress in isotropic and transversely isotropic rock," Int J Rock Mech Min Sci, vol.31, no. 1, pp 23-34, 1994.

[7] A.K. Singh, R. Singh, J. Maiti, R. Kumar, P.K. Mandal, "Assessment of mining induced stress development over coal pillars during depillaring," Int J Rock Mech Min Sci, vol.48, pp 805-818, 2011.

[8] H. Alehossein, B.A. Poulsen, "Stress analysis of longwall top coal caving," Int J Rock Mech Min Sci, vol.47, pp.30-41, 2010.

[9] R. Singh, S. Ram, A.K. Singh, S. Prasad and J. Buragohain, "Underground extraction of contiguous coal seams/sections consisting thin parting: A case study," The J South African Inst. of Min and Met, pp 17-28, Jan./Feb.-2004.

[10] P.K. Mandal, R. Singh, J. Maiti, A.K. Singh, R. Kumar, A. Sinha, "Underpinning-based simultaneous extraction of contiguous sections of thick coal seam under weak and laminated parting”. Int J Rock Mech Min Sci, vol.45, pp 11-28, 2008.

[11] R.D. Singh, "Principles and Practices of Modern Coal Mining”, Book published in 1997. 